\title{
PULLOUT RESISTANCE OF BURIED ANCHOR IN SAND
}

\author{
Kozo Tagaya ${ }^{\mathrm{i})}$, Ronald F. Scotri ${ }^{\mathrm{i})}$ and Hisao Aboshi ${ }^{\mathrm{i} i)}$
}

\begin{abstract}
This paper offers the estimation formulas of the pullout resistance of plate anchor in medium-to-dense sandy soil. The soil failure mechanism of anchor pullout can be divided into shallow and deep mechanisms. The solution of shallow anchor by Meyerhof (1973) and the formula of deep horizontal anchor by the theory of plasticity with the concept of cavity expansion will be introduced, and compared with the results of centrifuge model tests and the results of elastoplastic finite element analyses.

The main conclusions are as follows: (1) The solutions of the shallow anchor in arbitrary inclination and the deep horizontal anchor, the results of centrifuge model tests, and the results of finite element analyses showed good agreement; (2) The shape factor of finite length anchor has been clarified experimentally; (3) The critical relative depth from shallow anchor to deep anchor is 6-8 in the case of medium-to-dense dry sand having the angle of shear resistance of $32^{\circ}-42^{\circ}$.
\end{abstract}

Key words : anchor, angle of shear resistance, centrifuge model test, constitutive law, finite element method, pullout resistance, sand, shape factor, triaxial compression test (I GC: D 0/E 5)

\section{INTRODUCTION}

The study on the vertical pullout of horizontal shallow anchor was initiated by Balla (1961), who obtained the formula of the pullout resistance by solving Kötter's equation on the assumption that the failure surface was an arc. Matsuo (1967, 1968) analyzed the shallow anchor by extending the
Balla's method by assuming that the failure surface was a combination of a logarithmic spiral and a straight line. This method was further extended to the analysis of inclined anchor, by Katsumi and Nishihara (1978, 1980), by considering the stress normal to the failure surface which was neglected by Balla (1961). Vesić (1971, 1972) performed the analysis of vertical pullout of shallow

i) Chief Research Engineer, Steel Structure and Civil Engineering Research Laboratory, Hiroshima Research \& Development Center, Mitsubishi Heavy Industries, Ltd., 4-6-22, Kan-on-Shinmachi, Nishi-ku, Hiroshima 733.

ii) Professor, Department of Civil Engineering, California Institute of Technology, Pasadena, California 91125, USA.

iii) Professor, Department of Civil Engineering, Hiroshima University, Ohaza-Shitami, Saijo-cho, Higashi-Hiroshima, Hiroshima 724.

Manuscript was received for review on December 10, 1986.

Written discussions on this paper should be submitted before April 1, 1989, to the Japanese Society of Soil Mechanics and Foundation Engineering, Sugayama Bldg. 4 F, Kanda Awaji-cho 2-23, Chiyoda-ku, Tokyo 101, Japan. Upon request the closing date may be extended one month. 
anchor by the theory of plasticity with the theory of cavity expansion.

Meyerhof and Adams (1968), and Meyerhof (1973) offered a general solution of shallow and deep anchors, by the theory of plasticity, indicating a well agreement between the theoretical value and the experimental value for the shallow anchor. In the case of deep anchor, however, the theoretical value becomes larger than the experimental value. In addition, they proposed the shape factor of finite length anchor.

Ovesen (1981) proposed the experimental formulas by the centrifuge model test, which gives the values larger than the experimental value for the deep anchor.

For the purpose of advancing a proposal on the design formula of the pullout resistances of a shallow anchor which has arbitrary inclined angle and a deep horizontal anchor buried in medium-to-dense sand, the theoretical investigations, centrifuge model tests and elastoplastic finite element analyses are performed in this paper.

\section{GENERAL SOLUTION OF ANCHOR PULLOUT RESISTANCE}

Buried anchors are divided into shallow and deep anchors by the difference in their failure mechanism, as shown by Vesić (1971), Meyerhof (1973), and others. The soil failure due to pullout of the former occurs in a range of small dimensionless buried depth (relative depth) $D_{f} / B$ and extends to the ground surface. The soil failure due to pullout of the latter occurs only within the soil when the dimensionless buried depth $D_{f} / B$ is great (e. g. $D_{f} / B=6-8$ for $\phi=32-42^{\circ}$ ). The ultimate pullout resistances of the shallow and deep anchors by the theory of plasticity are shown, as follows.

\section{1) Shallow Anchor}

The sophisticated solution of a shallow anchor by the theory of plasticity has been reported by Meyerhof (1973). Since the solution best explains the test values described later and is generally applicable, it is adopted in this paper. The ultimate pullout resistance on a two-dimensional (strip) anchor buried in sand at any angle is expressed by the following equation :

$$
Q_{u s}=\frac{1}{2} \gamma \frac{D_{0}{ }^{2}}{B} K_{b} A+\left(W_{S}+W_{A}\right) \cos \alpha
$$

where $Q_{u s}$ is ultimate pullout resistance of shallow anchor ; $\gamma$, effective unit weight of soil ; $D_{0}$, maximum depth of anchor ; $B$, width of anchor ; $K_{b}$, uplift coefficient of shallow anchor ; $A$, area of anchor ; $W_{S}$, effective weight of soil above anchor; $W_{A}$, effective weight of anchor; and $\alpha$, inclined angle of anchor. The uplift coefficient of shallow anchor $K_{b}$ was shown by Meyerhof (1973).

\section{2) Deep Horizontal Anchor}

The failure mechanism of a deep horizontal anchor is very similar to that of the point bearing capacity of a pile, as shown by Vesić (1975). He analyzed the point bearing of pile by the theory of plasticity into which the concept of cavity expansion was introduced. In this paper, the pullout resistance of a deep horizontal anchor can be obtained, as the failure mechanism of point bearing of pile turned upside down, by the twodimensional failure mechanism in Fig. 1.

In Fig. 1, the highly compressed wedge I formed on the front side of anchor pushes the radial shear zone II sideways into the plastic zone III. The ultimate pullout re-

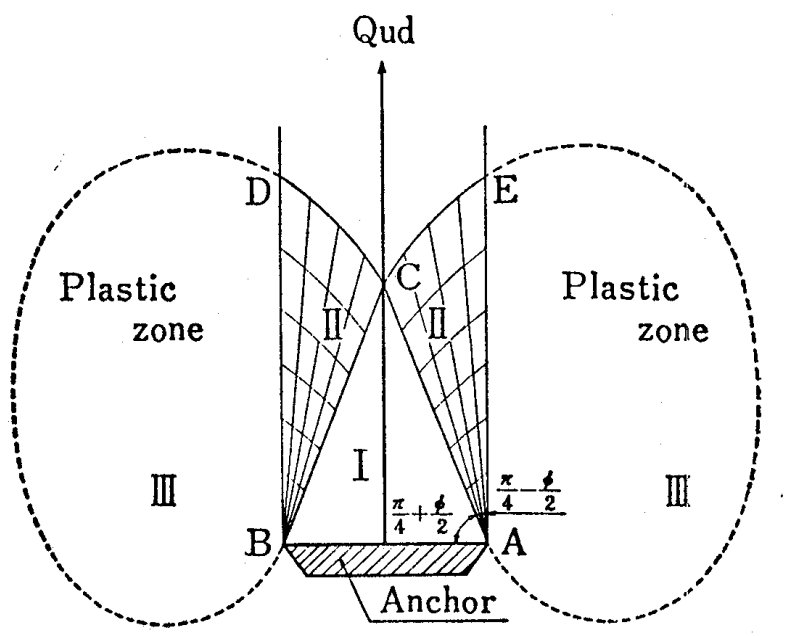

Fig. 1. Physical plane of deep anchor 
sistance can be shown as follows:

$$
q_{0}=\bar{\sigma} \tan ^{2}\left(\frac{\pi}{4}+\frac{\phi}{2}\right) \exp \cdot\left(\frac{\pi}{2}-\phi\right) \tan \phi
$$

Thus, the advancement of anchor into soil is made possible by lateral expansion of the soil along the long rectangular plates $\mathrm{AE}$ and $\mathrm{BD}$ by introducing the concept of cylindrical cavity expansion, as shown by Vesić (1975). With respect to the pile point bearing capacity, Vesić (1975) assumed the ultimate pressure needed to expand cavity $\bar{\sigma}$ as the product of the mean effective ground stress $\bar{q}$ of the plastic zone III and the cavity expansion factor $\bar{F}_{q}$ (Vesić, 1972). In this paper, his assumption is followed, as

$$
\bar{\sigma}=\bar{q} \bar{F}_{q}
$$

$\bar{q}$ is expressed two-dimensionally by the coefficient of earth pressure at rest $K_{0}$ and the initial vertical ground stress $\sigma_{V}$ as

$$
\bar{q}=\frac{1+K_{0}}{2} \sigma_{V}
$$

For the cavity expansion factor that is also to be considered two-dimensionally, the cylindrical cavity expansion factor is used and expressed by

$$
\bar{F}_{q}=\left(I^{\prime}{ }_{r r} \sec \phi\right)^{\sin \phi /(1+\sin \phi)}
$$

$I^{\prime}{ }_{r r}$ is the reduced rigidity index for the expansion of cylindrical cavity defined by Vesić (1972), which is expressed by the rigidity index of soil $I_{r}$, volumetric change parameter $\Delta$ of plastic zone III and the angle of shear resistance $\phi$, as

$$
I^{\prime}{ }_{r r}=\frac{I_{r}}{1+I_{r} \Delta \sec \phi}
$$

Since the anchor plate makes a volume behind it for the displaced volume in front of it to move into (that is, the increment of plastic volumetric strain in zone III is zero), the volume change parameter $\Delta$, as used by Vesić (1972), can be regarded as unity. The rigidity index $I_{r}$ is defined by Vesić (1972) as shown in Eq. (7).

$$
I_{r}=\frac{E}{2(1+\nu)(c+\bar{q} \tan \phi)}
$$

In this analysis of a deep horizontal anchor to be buried in the medium-to-dense sand, it may be considered that, in Eq. (7), the Young's modulus of the soil $E$ will take a relatively large value (more than several ten-thousands $\mathrm{kPa}$, for example); the angle of shear resistance $\phi$, the same value of more than $32^{\circ}$ as that of the sand used in the centrifuge model test, as described later ; the Poisson's ratio, about 0.3 ; and the cohesion $c$, zero. Although the mean effective ground stress $\bar{q}$ is determined by the buried depth of anchor and the coefficient of earth pressure at rest $K_{0}$, the rigidity index $I_{r}$ will become several hundreds when the buried depth in practice of construction and the coefficient of earth pressure at rest $K_{0}$ proposed by Jaky, as described later, are considered. Also, according to Vesić (1965), the rigidity index $I_{r}$ is 100 to 500 for loose to dense sand. For medium-to-dense sand, the rigidity index $I_{r}$ has the greater number (300-500) for the greater $\vec{q}$. Therefore, for the entire practical range of $I_{r}$, the value of $\bar{F}_{q}$ becomes 1, and Eqs. (6) and (5) become, as follows, respectively:

$$
\begin{aligned}
& I_{r r}^{\prime}=\frac{1}{\sec \phi} \\
& \bar{F}_{q}=1
\end{aligned}
$$

From Eqs. (3), (4) and (9), Eq. (2) becomes, as follows:

$$
q_{0}=\frac{1+K_{0}}{2} \sigma_{V} \tan ^{2}\left(\frac{\pi}{4}+\frac{\phi}{2}\right) \exp \cdot\left(\frac{\pi}{2}-\phi\right) \tan \phi
$$

The coefficient of earth pressure at rest $K_{0}$ is expressed by the angle of shear resistance $\phi$ (for example, Jaky, 1944 ; Yamaguchi, 1972, etc.), and the effective vertical ground stress $\sigma_{V}$, by the effective unit weight of soil $\gamma$ and the depth of anchor $D_{f}$. For the coefficient of earth pressure at rest $K_{0}$, Jaky's proposal is adopted in this paper, as follows :

$$
\begin{aligned}
& K_{0}=1-\sin \phi \\
& \sigma_{V}=\gamma D_{f}
\end{aligned}
$$

The following can be finally obtained by substituting Eqs. (11) and (12) in Eq. (10): $g_{0}=\frac{2-\sin \phi}{2} \gamma D_{f} \tan ^{2}\left(\frac{\pi}{4}+\frac{\phi}{2}\right) \exp \cdot\left(\frac{\pi}{2}-\phi\right) \tan \phi$ 


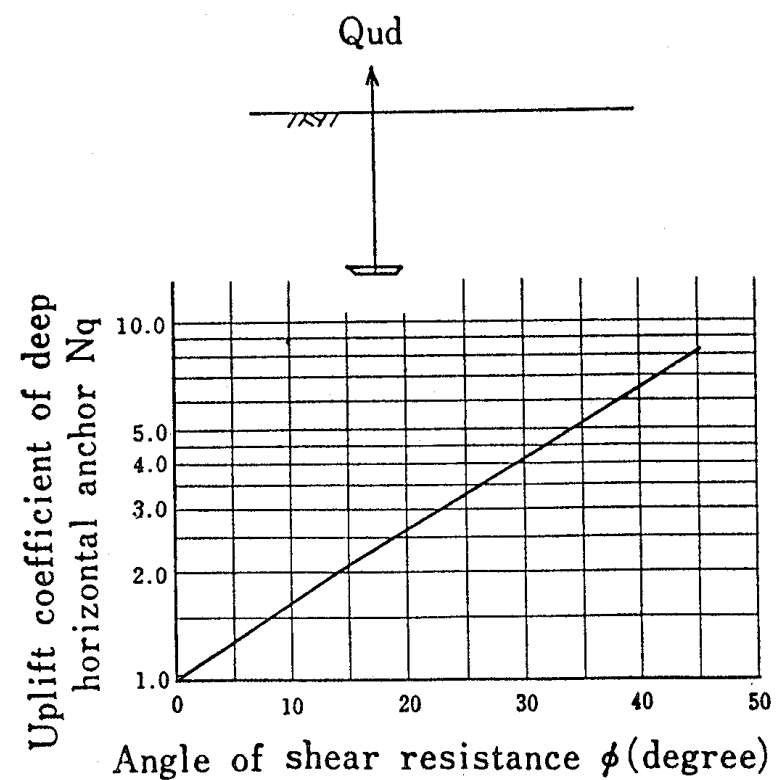

Fig. 2. Uplift coefficient of deep horizontal anchor

Since the total ultimate pullout resistance $Q_{u d}=q_{0} \times A$, Eq. (13) can be modified, as

$$
Q_{u d}=N_{q} \gamma D_{f} A
$$

where

$$
N_{q}=\frac{2-\sin \phi}{2} \cdot \tan ^{2}\left(\frac{\pi}{4}+\frac{\phi}{2}\right) \exp \cdot\left(\frac{\pi}{2}-\phi\right) \tan \phi
$$

$N_{q}$ is called herein the uplift coefficient of deep horizontal anchor.

From Eq. (14), it is clear that the dimensionless quantity $Q_{u d} / A \gamma D_{f}$ of the ultimate pullout resistance is a function of the angle of shear resistance of soil $\phi$.

The uplift coefficient of deep horizontal anchor $N_{q}$ obtained for various values of $\phi$ is shown in Fig. 2. In the design of actual anchor, the effective weight of anchor $W_{A}$ can be added to Eq. (14), as follows :

$$
Q_{u d}=N_{q} \gamma D_{f} A+W_{A}
$$

The equation of the coefficient of earth pressure at rest $K_{0}$ proposed by Jaky (1944) used in the above analysis of a deep horizontal anchor is somewhat different from the equations of the coefficient of earth pressure at rest $K_{0}$ proposed by other researchers (for example, Yamaguchi, 1972). However, since the difference among the coefficients of earth pressure at rest $K_{0}$ obtained by these equations is so small for the practical range of the angle of shear resistance $\phi$, Jaky's equation (1944) was used in this study.

\section{3) Determination of Shallow Horizontal} Anchor and Deep Horizontal Anchor

In Section 1) of this Chapter, the Meyerhof's estimation equation (1983) of pullout resistance of a shallow anchor that causes a soil failure line reaching the ground surface is referred to. In Section 2), an estimation equation of pullout resistance of a deep horizontal anchor that causes soil failure only in its vicinity was proposed. When the buried depth of anchor $D_{f}$ is changed from shallow to deep, the failure pattern of a shallow anchor will be indicated until the anchor reaches a certain depth, and then, the failure pattern of a deep anchor will be shown. This transition point from shallow anchor to deep anchor is called here the critical depth $D_{f_{c r}}$. In designing an anchor, it is necessary to determine which pattern of the two failures would be caused depending on the buried depth $D_{f}$ by obtaining this critical depth $D_{f_{c r}}$, that is, which equation should be used, Eq. (1) or (16). This critical depth $D_{f_{c r}}$ can be determined by the following procedure.

From equating Eq. (1) and Eq. (16) disregarding the effective weight of anchor $W_{A}$ that is not related to the soil failure mechanism, and as $D_{0}=D_{f}$ for horizontal anchor a quadratic equation of $D_{f}$ can be obtained, which will give two solutions. From the physical meaning that the critical depth $D_{f_{c r}}$ indicates the transition point from shallow anchor (the region of the quadratic equation about the depth $D_{f}$ ) to deep anchor (the linear region about the depth $D_{f}$ ), the greater of the two solutions will become the critical depth $D_{f_{c r}}$. The ultimate pullout resistance can be obtained by using Eq. (1) for a shallower anchor and Eq. (16) for a deeper anchor than the critical depth $D_{f_{c r}}$.

\section{4) Shape Factor}

Meyerhof and Adams (1968) considered that the shape effect of the vertical pullout 
of horizontal rectangular anchor was similar in each $B / 2$ portion on both ends to that of a circular anchor and in the middle portion of $\left(L_{A}-B\right)$ to that of a strip anchor ( $L_{A}$ : length of anchor, $B:$ width of anchor). Meyerhof (1973) also proposed based on experiment that the uplift coefficient of a rectangular anchor could be obtained by interpolating uplift coefficients of a strip and a square anchor by the width to length ratio $B / L_{A}$ and that a circular anchor could be analyzed as a square anchor having the same area.

As above, the shape effect of a buried anchor has not yet been definitely theorized, but only possibly determined by experiments. From the practical point of view, in this paper, the shape effect of a buried anchor is defined based on Meyerhof and Adams' concept (1968), as below.

When the shape factor of a strip anchor $S_{s t}$ is taken as 1 , a square anchor will have the number of vertical planes passing through the anchor edges twice that of the former giving the latter's shape factor $S_{s q}$ as 2 . Considering that the shape factor of a rectangular anchor is obtained by interpolation between the shape factor of a square anchor and that of a strip anchor, the general shape factor $S_{h}$ can be expressed by:

$$
S_{h}=1.0+\frac{B}{L_{A}}
$$

For a square and a circular anchor, $S_{s q}=$ $S_{c}=2.0$. Although no sufficiently reviewed data are available, the variation in the shape effect with the inclined angle of anchor $\alpha$ is little observed by the centrifuge model tests, as described later. A linear increase to the relative depth $D_{f} / B$ of the shape factor, as presented by Meyerhof (1973), will not be considered in this paper because such a result has not been obtained in the laboratory test of a buried anchor in a centrifugal field, as described later.

Since Eq. (17) can relatively well explain the test results, it is applied to a shallow and a deep anchor to obtain the general equation for pullout resistance of a buried anchor, as follows :
For a shallow anchor :

$$
Q_{u s}=\frac{1}{2} K_{b} \gamma-\frac{D_{0}^{2}}{B} A S_{h}+\left(W_{S}+W_{A}\right) \cos \alpha
$$

For a deep horizontal anchor:

$$
Q_{u d}=N_{q} D_{f} A S_{h}+W_{A}
$$

\section{CENTRIFUGE MODEL TEST ON PULL- OUT RESISTANCE OF BURIED AN- CHOR IN SAND}

The results of the centrifuge model tests that were performed to clarify the pullout resistance of an anchor buried in sand were compared with the solutions of the theory of plasticity and the results of the elastoplastic finite element analyses based on the Lade's constitutive law (1972, 1975, 1976).

\section{1) Models}

Circular and rectangular anchor models of steel with the rigid steel shaft as shown in Fig. 3 were used in the test. The scale was about $1 / 90-1 / 100$ by assuming that the length or diameter of actual anchor is about $3-10$ meters. Their side surfaces were cut at $45^{\circ}$ to eliminate the effect of side friction.

\section{2) Sand Used}

Ottawa Sand and Toyoura Sand were used as test sand. Their soil characteristics are
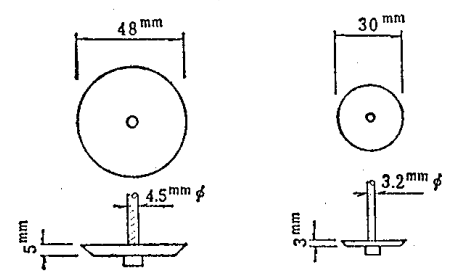

Large circular anchor.

$$
\text { Small circular }
$$
anchor

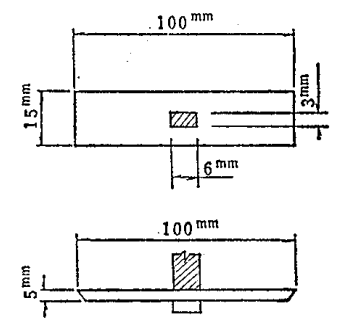

long rectangular anchor
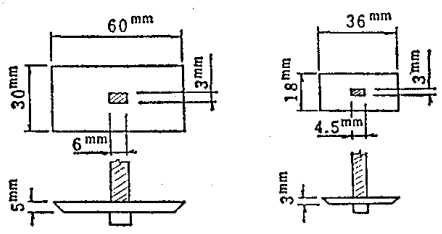

Large rectangular Small rectangular
anchior

Fig. 3. anchor models 
Table 1. Average properties of model ground for anchor pullout test

\begin{tabular}{|c|c|c|c|c|c|c|c|}
\hline Test sand & {$\left[\begin{array}{c}50 \text { percent } \\
\text { grain size } \\
D_{90}(\mathrm{~mm})\end{array} \mid\right.$} & $\begin{array}{c}\text { Coefficient of } \\
\text { uniformity } \\
U_{c} \\
\end{array}$ & $\begin{array}{c}\text { Specific } \\
\text { gravity } \\
\text { Gs }\end{array}$ & 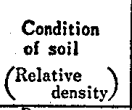 & $\begin{array}{l}\text { Effective } \\
\text { unit weight } \\
\text { of soi) } \\
\gamma\left(\mathrm{kN} / \mathrm{m}^{\prime}\right)\end{array}$ & 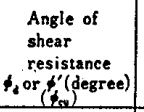 & $\begin{array}{l}\text { Type of } \\
\text { triaxial } \\
\text { compression } \\
\text { test }\end{array}$ \\
\hline \multirow{2}{*}{$\begin{array}{l}\text { Ottawa } \\
\text { Sand }\end{array}$} & \multirow{2}{*}{0.47} & \multirow[b]{2}{*}{2.16} & \multirow[b]{2}{*}{2.69} & $\begin{array}{l}\text { Dry } \\
\text { Loose } \\
(56.7 \%) \\
\end{array}$ & 16.2 & 31.6 & $\begin{array}{l}\text { Consolidated } \\
\text { drained test } \\
\text { (CD-test) }\end{array}$ \\
\hline & & & & $\begin{array}{l}\text { Dry } \\
\text { Dense } \\
(76.7 \%) \\
\end{array}$ & 16.8 & 35.1 & $\begin{array}{l}\text { Consolidated } \\
\text { drained test } \\
\text { (CD-test) }\end{array}$ \\
\hline $\begin{array}{l}\text { Toyoura } \\
\text { Sand }\end{array}$ & 0.17 & 1.49 & 2.64 & $\begin{array}{l}\text { Dry } \\
\text { Dense } \\
(83.5 \%)\end{array}$ & 15.5 & 42.0 & $\begin{array}{l}\text { Consolidated } \\
\text { drained test } \\
\text { (CD-test) }\end{array}$ \\
\hline
\end{tabular}
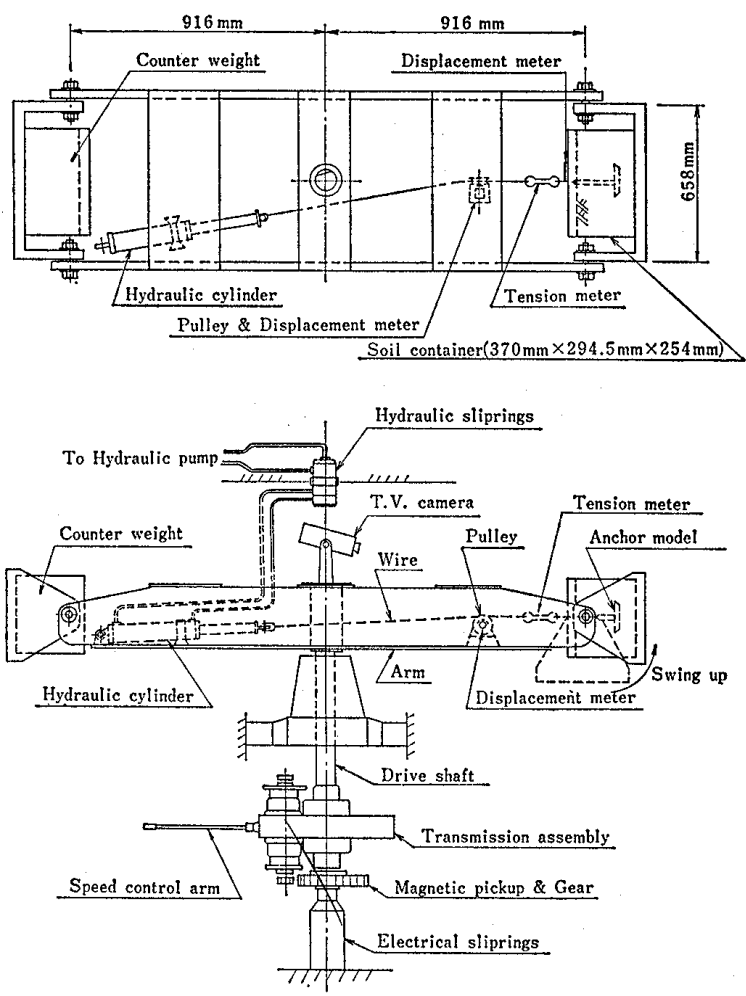

Fig. 4. Centrifugal testing machine of California Institute of Technology

shown in Table 1. Both Sands were used under the furnace-dried condition.

3) Centrifugal Testing Machine and Instrumentation

In these tests, two centrifugal testing machines of California Institute of Technology, as shown in Fig. 4, and Tokyo Institute of Technology, as shown by Yamaguchi, Kimura and Fujii (1977), were used. The former is provided with two soil containers of $370 \mathrm{~mm} \times 294.5 \mathrm{~mm} \times 254 \mathrm{~mm}$ (parallelepiped) and $152 \mathrm{~mm} \phi \times 617 \mathrm{~mm}$ (cylindrical) having a radius of rotation $916 \mathrm{~mm}$ and rotating at a maximum acceleration of 175 $\mathrm{g}$, and the latter, with one soil container of $500 \mathrm{~mm} \times 100 \mathrm{~mm} \times 300 \mathrm{~mm}$ having a radius of rotation $1180 \mathrm{~mm}$ and rotating at a maximum acceleration of $300 \mathrm{~g}$.

Fig. 4 also shows the instrumentation system of the centrifugal testing machine of California Institute of Technology. The anchor is pulled out by a wire connected to a hydraulic cylinder at the top of its shaft. This wire is provided with a pulley in its midway equipped with a potentiometer for measuring displacement and with a tension meter directly connected to the top of anchor shaft for measuring the pullout force. To detect the initial movement of anchor, a displacement meter of cantilever type was installed on the top of the anchor shaft. These meters were calibrated before putting them into use. The hydraulic system for loading was powered by a hydraulic pump provided outside the machine through a hydraulic slipring.

In case of the centrifugal testing machine of Tokyo Institute of Technology, loads were applied by a screw-type loading jack powered by a reduction motor. Displacement and pullout force were measured by a differential transformer-type displacement meter and a load cell inserted between the anchor model and the loading jack, respectively.

\section{4) Test Procedure}

The test procedure applied is, as follows:

(1) Ottawa Sand or Toyoura Sand measured to the weight as specified is placed into the soil container in layers of $20-30 \mathrm{~mm}$. The soil in each layer is compacted all over to an even density with a vibrator and a compacting rod. When the test soil is filled 
Table 2. Test cases

\begin{tabular}{|c|c|c|c|c|c|c|c|}
\hline & \multirow[b]{2}{*}{ Models } & \multirow[b]{2}{*}{$\begin{array}{c}\text { Name } \\
\text { of soil } \\
\end{array}$} & \multirow{2}{*}{$\begin{array}{l}\text { Unit weight of } \\
\text { soil } \gamma \mathrm{kN} / \mathrm{m}^{3} \\
\left(\begin{array}{l}\text { Relative } \\
\text { density } \mathrm{Dr} \%\end{array}\right)\end{array}$} & \multirow{2}{*}{$\begin{array}{l}\text { Inclined } \\
\text { angle of } \\
\text { anchor } \\
\alpha \text { (degree) }\end{array}$} & \multicolumn{2}{|c|}{ Depth of anchor } & \multirow{2}{*}{$\begin{array}{c}\text { Acceleration } \\
\text { level } \\
\mathrm{G}_{\mathrm{l}} . \\
\end{array}$} \\
\hline & & & & & $\begin{array}{c}\text { Deptl } \\
\operatorname{Df}(m m) \\
\end{array}$ & $\begin{array}{c}\text { Relative } \\
\text { depth } \mathrm{D}_{\mathrm{f}} / \mathrm{B}\end{array}$ & \\
\hline \multirow{5}{*}{ Anchor } & $\begin{array}{l}\text { Circular } \\
(48 m m \phi)\end{array}$ & $\begin{array}{l}\text { Ottawa } \\
\text { Sand }\end{array}$ & $\begin{array}{c}16.8 \\
(76.7)\end{array}$ & 0,45 & $48.0-105.0$ & $1.13-2.71$ & $87.1-98.1$ \\
\hline & $\begin{array}{l}\text { Circular } \\
(30 m m \phi)\end{array}$ & $\begin{array}{l}\text { Ottawa } \\
\text { Sand }\end{array}$ & $\begin{array}{l}16.8 \\
(76.7)\end{array}$ & 0,45 & $38.5-151.0$ & $1.45-5.68$ & $88.4-101.1$ \\
\hline & $\begin{array}{l}\text { Rectangular } \\
(30 \mathrm{~mm} \times 60 \mathrm{~mm})\end{array}$ & $\begin{array}{l}\text { Ottawa } \\
\text { Sand }\end{array}$ & $\begin{array}{c}16.8 \\
(75.7)\end{array}$ & 0,45 & $48.0-114.0$ & $1.60-3.80$ & $87.8-97.6$ \\
\hline & $\begin{array}{l}\text { Rectangular } \\
(18 \mathrm{~mm} \times 36 \mathrm{~mm})\end{array}$ & $\begin{array}{l}\text { Ottawa } \\
\text { Sand }\end{array}$ & $\begin{array}{c}16.8,16.2 \\
(76.7,56.7)\end{array}$ & 0,45 & $41.0-505.5$ & $2.28-28.08$ & $88.6-128.0$ \\
\hline & $\begin{array}{l}\text { Rectangular } \\
(15 \mathrm{~mm} \times 100 \mathrm{~mm})\end{array}$ & $\begin{array}{l}\text { Toyoura } \\
\text { Sand }\end{array}$ & $\begin{array}{c}15.5 \\
(83.5)\end{array}$ & 0 & $45.0-105.3$ & $3.00-7.02$ & 40.0 \\
\hline
\end{tabular}

up to the level specified for the anchor model to be placed, the anchor is set at the specified position and inclined angle, and the test soil is added in layers, each of which is compacted as above. When the specified amount of soil has been placed, the height of the soil surface is measured to obtain the average unit weight of the soil (about 230 $\mathrm{mm}$ for parallelepiped container and about $550 \mathrm{~mm}$ for cylindrical container). The average relative densities of model ground of Ottawa Sand and Toyoura Sand were 76.7\% and $83.5 \%$, respectively.

(2) After a tension meter, displacement meter(s), loading equipment and a counterweight have been set, the centrifugal testing machine is rotated at the specified number

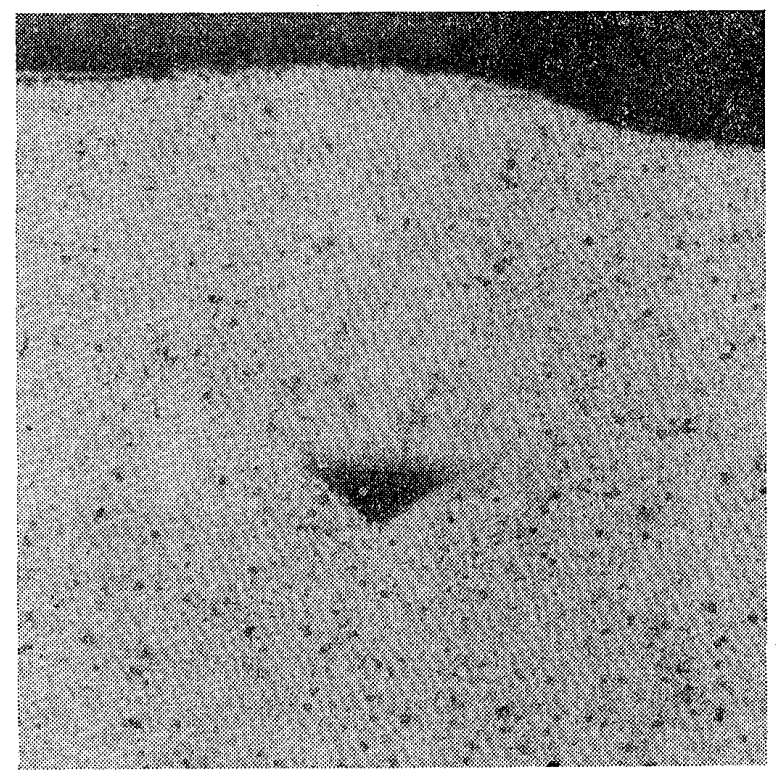

Photo.1. Failure pattern of shallow anchor of revolutions. The pullout force and the displacement of the anchor are measured as the anchor is being pulled out by remote control.

\section{5) Test Cases}

The tests were performed by changing the buried depth of anchor (shallow and deep), the inclination of anchor (horizontal and $45^{\circ}$ ), (the anchor was always pulled out perpendicular to the anchor plane through its center), the type of anchor (rectangular and circular), as shown in Table 2.

6) Test Results and Discussion

(1) Method of data anlysis

In this paper, the pullout resistance of

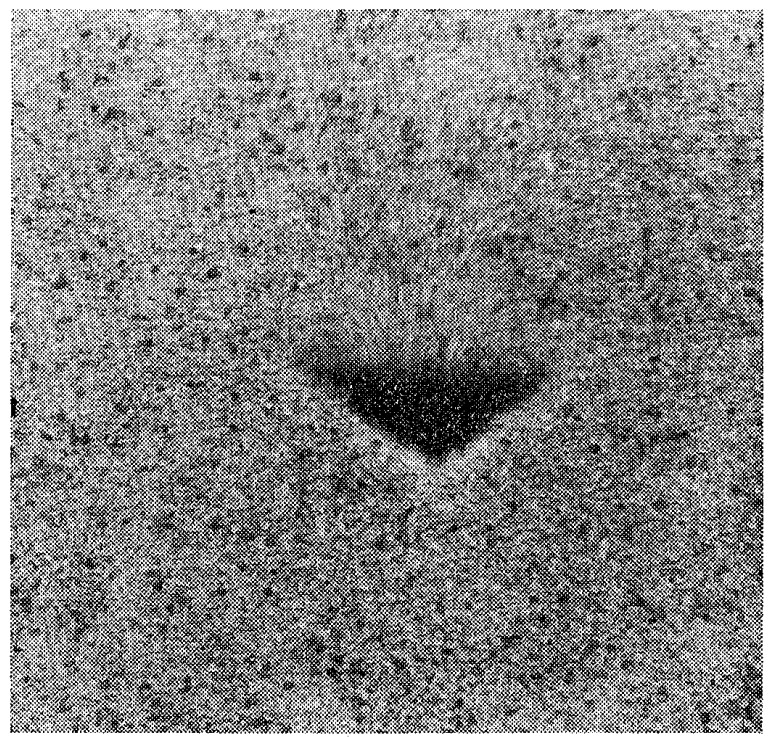

Photo.2. Failure pattern of deep anchor 
anchor only will be discussed by performing a data analysis without the shaft resistance and without the weight of anchor and shaft based on the preliminary test.

(2) Failure mechanism of buried anchor Using the small rectangular anchor, the two-dimensional visualized qualitative model test in the $1 \mathrm{~g}$ field was performed in a transparent plastic box showing the failure mechanisms of ground on the shallow and deep anchors, which were observed by the photography. In case of the shallow anchor, two arciform failure lines are caused from its edges toward the ground surface as shown in Photo. 1, while, in case of the deep anchor, its failure mechanism consists of a rigid region of soil in front of the anchor, two logarithmic spiral shearing regions connected thereto and two regions driven horizontally by the shearing regions as shown in Photo. 2. These failure mechanisms are in good agreement with the assumption in the analysis by plasticity, as described before.

(3) Relation between ultimate pullout resistance and buried depth

Figs. 5-7 show the relation between the dimensionless ultimate pullout resistance $Q_{u} / A_{\gamma} G_{L} D_{f}$ and the relative buried depth $D_{f} / B$ of the anchor $\left(G_{L}\right.$ : acceleration level in centrifugal field). These figures involve thet heoretical lines by the theory of plasticity and the analyzed values by the finite element method, as detailed later. These theoretical values also include the three-di-

$$
\text { Dimensionless ultimate pullout resistance } \frac{Q_{u}}{A \gamma G_{L} D_{f}}
$$

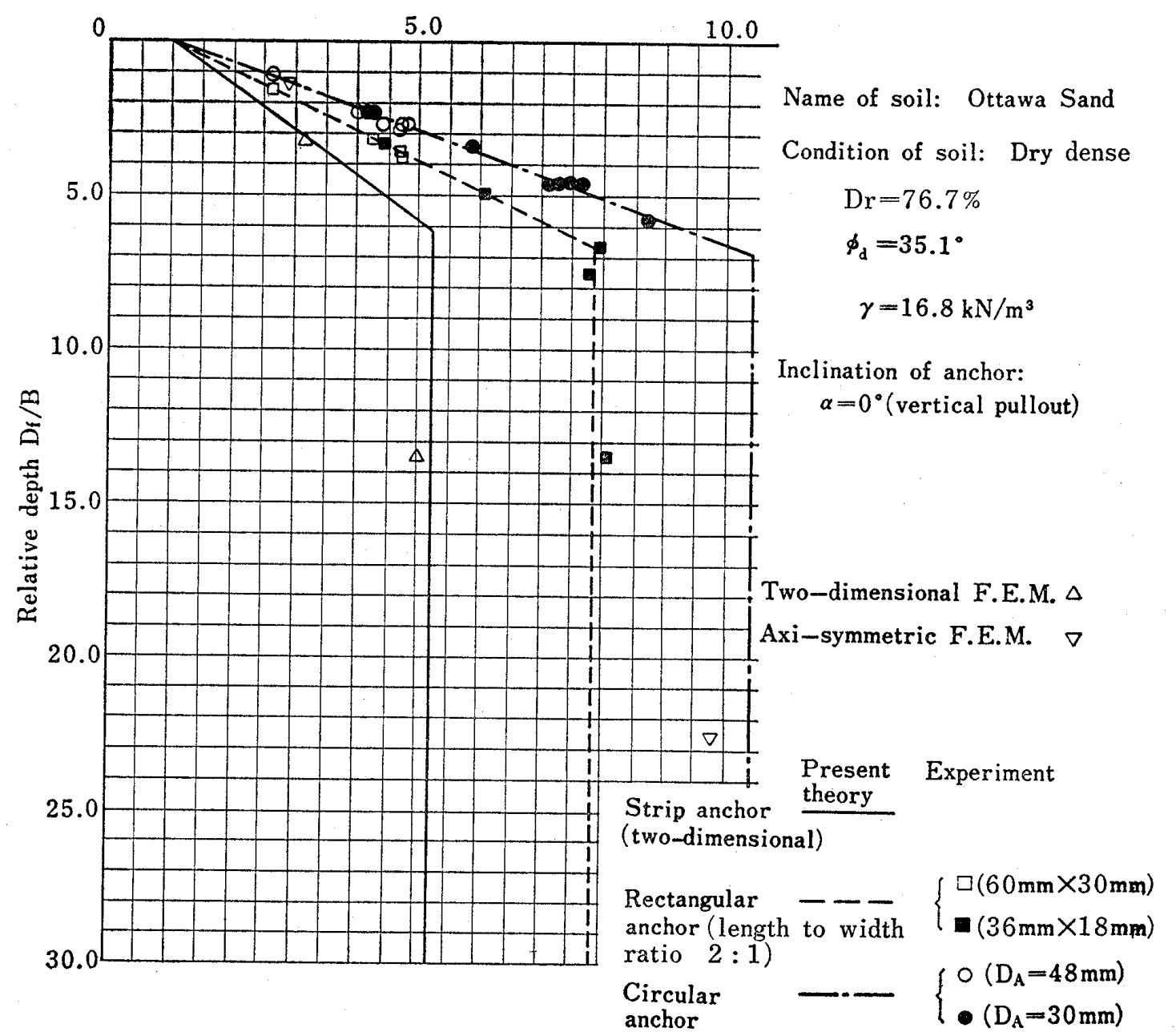

Fig. 5. Relation between dimensionless ultimate pullout resistance and relative depth (Vertical pullout, dry dense Ottawa Sand) 


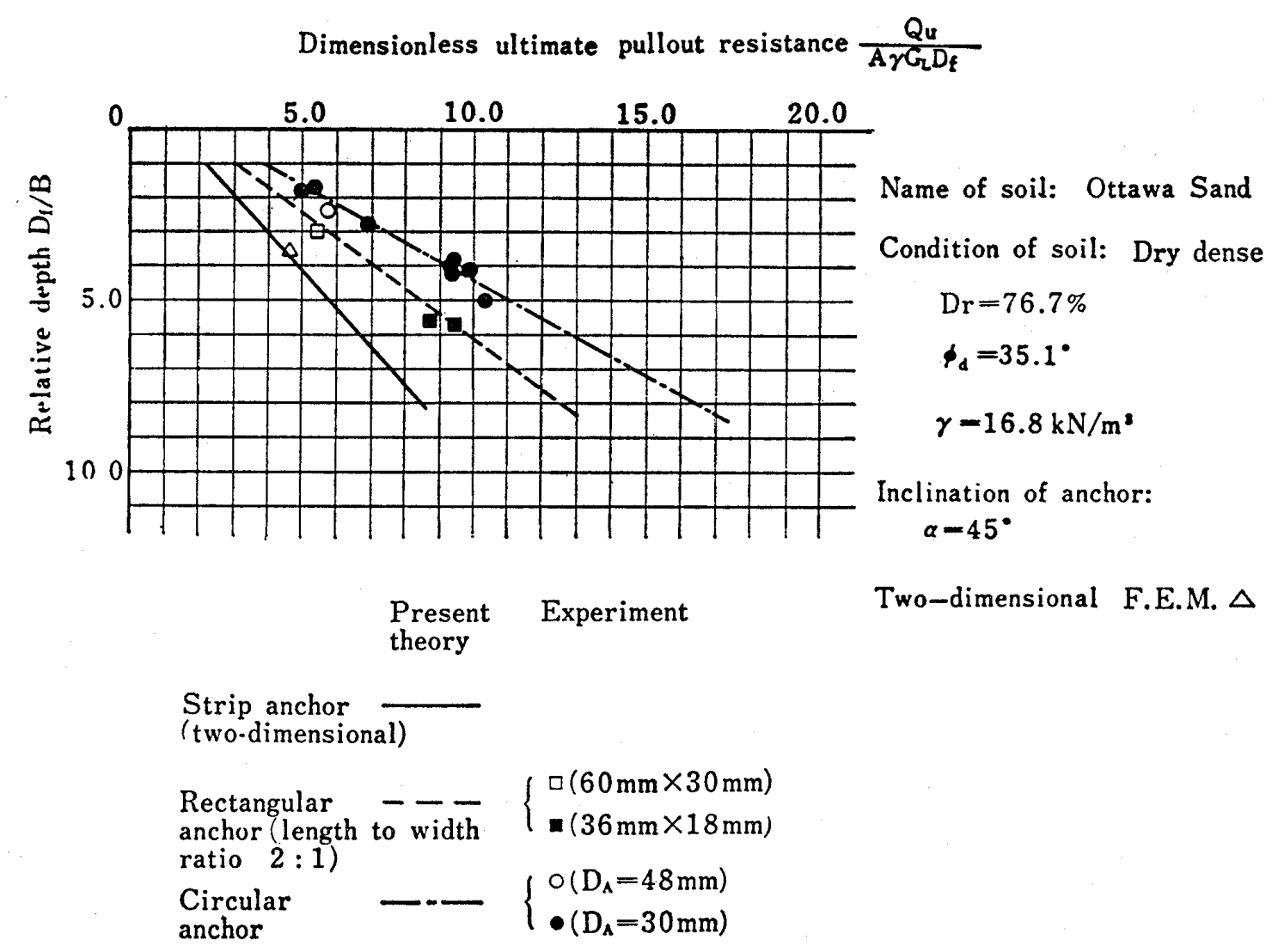

Fig. 6. Relation between dimensionless ultimate pullout resistance and relative depth (45ำ-pullout, dry dense Ottawa Sand)

mensional shape effect, as described before. The angle of shear resistance to obtain these theoretical lines has been obtained from the results of the triaxial compression test.

From the Ovesen's proposal (1981) that a circular anchor is equal in pullout resistance to a square anchor having the equal area to the former, the side length of the square anchor having the same area as the circular anchor was taken as a representative length in the data analysis $\left(B=\sqrt{\pi / 4} \cdot D_{A}=0.886 D_{A}\right)$. Fig. 8 shows all the data converted into the shape factor of the two-dimensional anchor (to be 1.0) using the equation of shape factor given by Eq. (17). This figure indicates the three-dimensional effect remains almost unchanged in depth.

From the above, the following can be said :

a) The three-dimensional effect (shape factor) of the buried anchor in dense Ottawa Sand will not be changed in depth.

b) The shape factor $S_{h}$ taken as $S_{h}=1.0+$
$B / L_{A}$ from the above discussion can well explain the experimental values and be sufficiently applicable to design. Also, the equivalent side length of a circular anchor B can be expressed by $0.886 D_{A}$.

c) In the relation between the dimensionless ultimate pullout resistance and the relative depth, the theoretical values are in good agreement with the experimental values.

d) As clear from the figures showing the relation between the dimensionless ultimate pullout resistance and the relative depth, there is a critical relative depth $\left(D_{f} / B\right)_{c r}$ between shallow anchor and deep anchor, which varies depending on the angle of shear resistance achieved $\left(D_{f} / B\right)_{c r}=6-8$ at $\phi=32^{\circ}-$ $42^{\circ}$.

7) Elastoplastic Finite Element Analysis of Buried Anchor in Ottawa Sand

Two-dimensional and axi-symmetric finite element analyses were performed on dry Ottawa Sand based on the constitutive law 
Dimensionless ultimate pullout resistance $\frac{Q u}{A \gamma G_{L} D_{f}}$

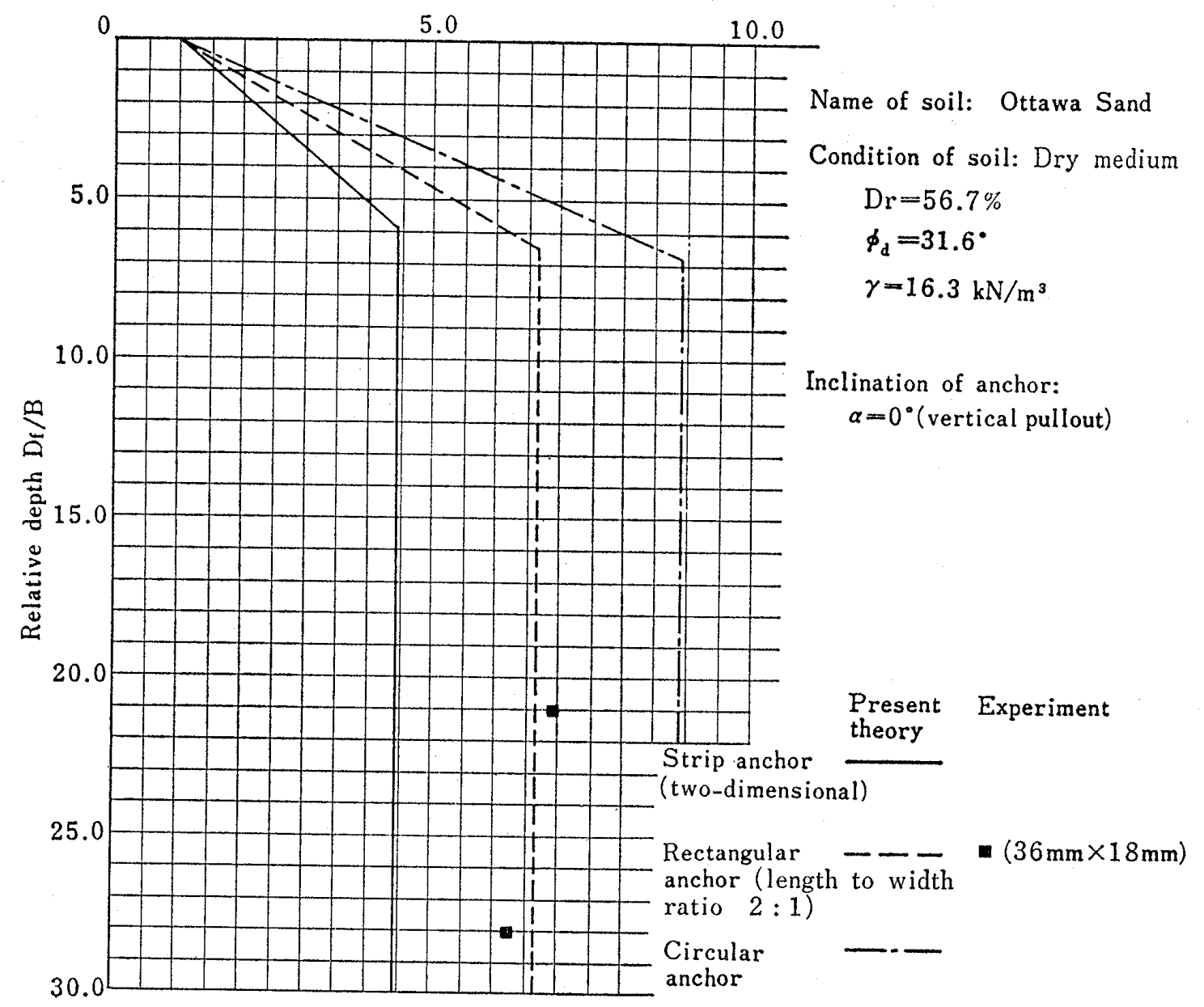

Fig. 7. Relation between dimensionless ultimate pullout resistance and relative depth (Vertical pullout, dry medium Ottawa Sand)

by Lade (1972, 1975, 1976).

These finite element analysis programs have been prepared in the load increment method using the two-dimensional isoparametric element. Their applicability to anchor problem was discussed by Tagaya, Tanaka and Aboshi (1983).

From the results of the triaxial compression tests of dry Ottawa Sand, the soil constants necessary for elastoplastic finite element analysis based on the constitutive law by Lade $(1972,1975,1976)$ are obtained, as given in Table 3 . Based on these constants, the finite element analysis technique was applied to the calculation of the buried anchors in the cases given in Table 4, which also involves the results of analyses. All analysis results as given in Table 4 are plotted in Figs. 5 and 6, and Fig. 13, as given before and later, respectively. The boundary conditions used in these analyses are : the bottom and the side being free in the horizontal and vertical directions, respectively. The ultimate pullout resistance was determined at the point showing a sudden increase in displacement in the load-displacement curve.

Figs. 9-12 show the results of typical analyses under the same conditions as those of the centrifuge model tests, as described before, provided the tests have been performed three-dimensionally and the finite element analyses, two-dimensionally. Figs. 9-12 show the spread of plastic zone and the displacement of anchor or the deformation of soil in typical analysis cases (shallow and 

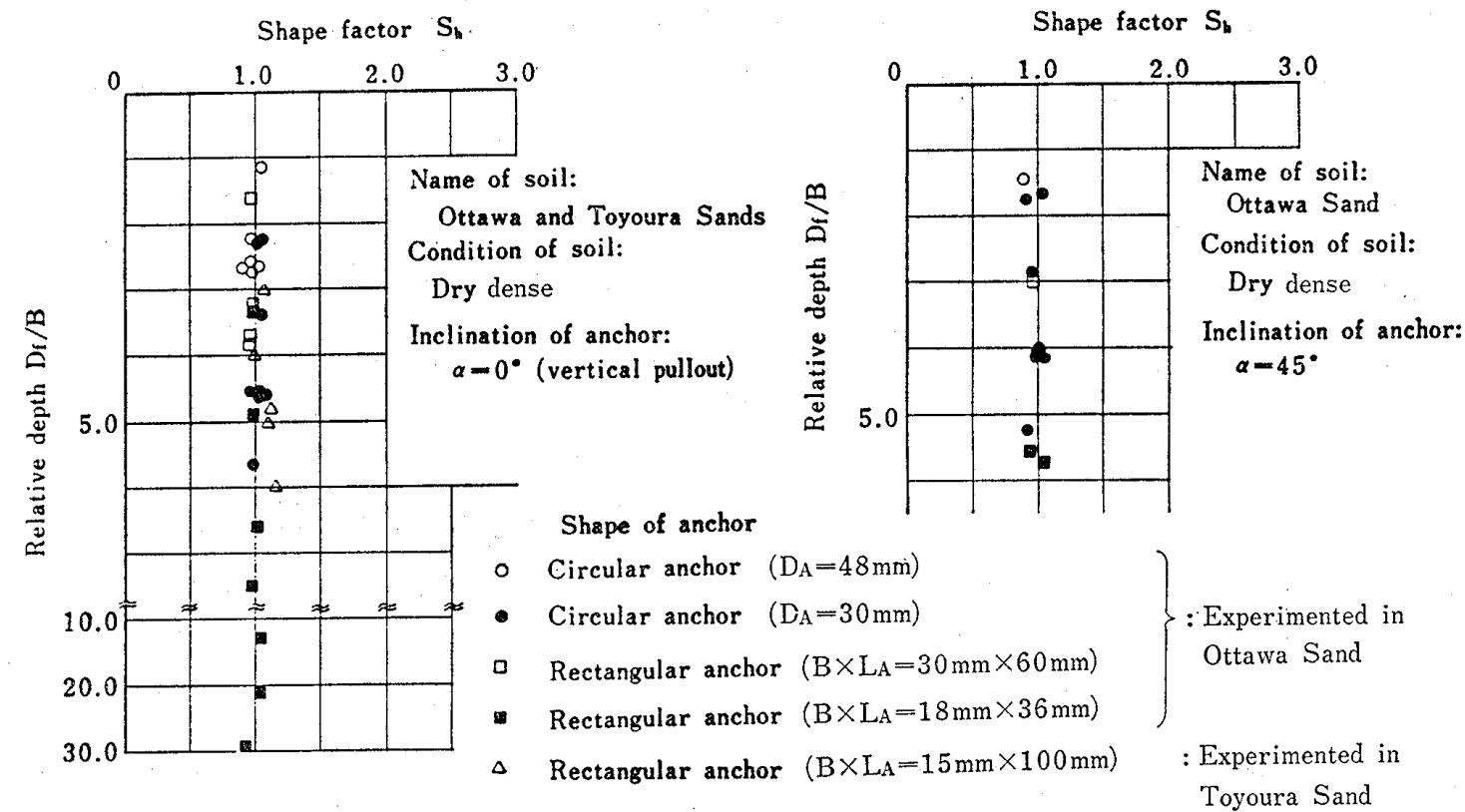

Fig. 8. Three-dimensional effect of anchor pullout (shape factor) in depth direction

Table 3.

Soil properties of dry dense Ottawa Sand for elastoplastic finite element analysis

\begin{tabular}{c|c}
\hline$K_{u r}$ & 1276.2 \\
\hline$n$ & 0.55 \\
\hline$\nu$ & 0.287 \\
\hline$K_{t}$ & 35.26 \\
\hline$K_{f}$ & 50.703 \\
\hline$R_{f}$ & 0.909 \\
\hline$M$ & 0.00016 \\
\hline$\ell$ & 0.80 \\
\hline$A_{I}$ & 0.72 \\
\hline$A_{2}$ & 5.80 \\
\hline$\phi_{d}$ & 35.10 \\
\hline
\end{tabular}

Table 4. Cases and results of elastoplastic finite element analyses for anchor buried in dry dense Ottawa Sand

\begin{tabular}{|c|c|c|c|c|c|c|}
\hline Case number & 1 & 2 & 3 & 4 & 5 & 6 \\
\hline Method of analysis & $2 \mathrm{D}$ & $2 \mathrm{D}$ & $2 \mathrm{D}$ & $2 \mathrm{D}$ & AXI & AXI \\
\hline $\begin{array}{ll}\text { Pullout angle } & \text { (Inclination } \\
\text { of anchor) } & a \text { (degree) }\end{array}$ & 0 & 0 & 45 & 90 & 0 & 0 \\
\hline $\begin{array}{l}\text { Width or diameter of anchor } \\
\left.\text { (effective width } B \text { or } D_{A}\right)(m m)\end{array}$ & $\begin{array}{c}30 \\
(30)\end{array}$ & $\begin{array}{c}18 \\
(18)\end{array}$ & $\begin{array}{c}30 \\
(30) \\
\end{array}$ & $\begin{array}{c}30 \\
(30)\end{array}$ & $\begin{array}{c}48 \\
(42.5) \\
\end{array}$ & $\begin{array}{c}18 \\
(15.9)\end{array}$ \\
\hline Depth of anchor $D_{f} \quad(\mathrm{~nm})$ & 96 & 241.3 & 108 & 45 & 48 & 360 \\
\hline $\begin{array}{l}\text { Relative depth of anchor } \\
\qquad D_{f} / B\end{array}$ & 3.20 & 13.41 & 3.60 & 1.50 & 1.13 & 22.64 \\
\hline $\begin{array}{l}\text { Effective unit weight of soil } \\
\qquad \gamma \quad\left(\mathrm{kN} / \mathrm{m}^{3}\right)\end{array}$ & 16.8 & 16.8 & 16.8 & 16.8 & 16.8 & 16.8 \\
\hline Acceleration level $G_{L}$ & 92.3 & 94.9 & 97.7 & 100.0 & 94.9 & 94.9 \\
\hline $\begin{array}{l}\text { Ultimate pullout resistance } \\
\qquad Q_{u}(\mathrm{~N} / \mathrm{cm} \text { or } \mathrm{N})\end{array}$ & $\begin{array}{c}141.2 \\
(\mathrm{~N} / \mathrm{cm})\end{array}$ & $\begin{array}{c}348.1 \\
(\mathrm{~N} / \mathrm{cm})\end{array}$ & $\begin{array}{l}249.7 \\
(\mathrm{~N} / \mathrm{cm})\end{array}$ & $\begin{array}{l}130.4 \\
(\mathrm{~N} / \mathrm{cm})\end{array}$ & $\begin{array}{l}366.3 \\
(N)\end{array}$ & $\begin{array}{c}1417.2 \\
(\mathrm{~N})\end{array}$ \\
\hline $\left.\begin{array}{l}\text { Dimensionless ultimate } \\
\text { pullout resistance } Q_{u} / A \gamma G_{L} D_{f} \\
\text { Dimensionless ultimate } \\
\text { pullout resistance by } \\
\text { theory of plasticity }\end{array}\right)$ & $\begin{array}{c}3.17 \\
(3.19)\end{array}$ & $\begin{array}{c}5.04 \\
(5.22)\end{array}$ & $\begin{array}{c}4.70 \\
(4.47)\end{array}$ & $\begin{array}{l}5.76 \\
(4.84)\end{array}$ & $\begin{array}{l}2.65 \\
(2.56)\end{array}$ & $\begin{array}{c}9.74 \\
(10.44)\end{array}$ \\
\hline
\end{tabular}

21) : Two-dimensional elastoplastic finite element analysis

AXI: Axi-symmetric elastoplastic finite element analysis deep two-dimensional analyses). $K, K_{f}$ and $K_{t}$ are the stress level defined as $I^{3}{ }_{1} / I_{3}$, the value of $K$ at failure and the value of $K$ at threshold for plastic straining, respectively, in the Lade's constitutive law (1972,
1975, 1976).

From Table 4 and Figs. 9-12, the following is shown :

(1) The failure and the deformation of the ground by pullout of a buried anchor are 


\begin{tabular}{|c|c|}
\hline Method of analysis & Two-dimensional F.E.M. \\
\hline Acceleration level & $\mathrm{G}_{\mathrm{L}}=92.3$ \\
\hline Name of soil & Ottawa Sand \\
\hline Condition of soil & $\begin{array}{l}\text { Dry dense } \operatorname{Dr}=76.7 \% \\
\phi_{\mathrm{d}}=35.1^{\circ}, \gamma=16.8 \mathrm{kN} / \mathrm{m}^{3}\end{array}$ \\
\hline Width of anchor & $B=30 \mathrm{~mm}$ Relative depth \\
\hline Depth of anchor & $D_{\mathrm{i}}=96 \mathrm{~mm} \quad \mathrm{D}_{\mathrm{i}} / \mathrm{B}=3.20$ \\
\hline Inclination of anchor & $\alpha=0^{\circ}$ (vertical pullout) \\
\hline
\end{tabular}

Number of elements : 546

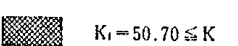

$47.61 \cong \mathrm{K}<50.70$

QIZZ $44.53 \leqq K<47.6$

EIIY $41.34 \leqq K<44.53$

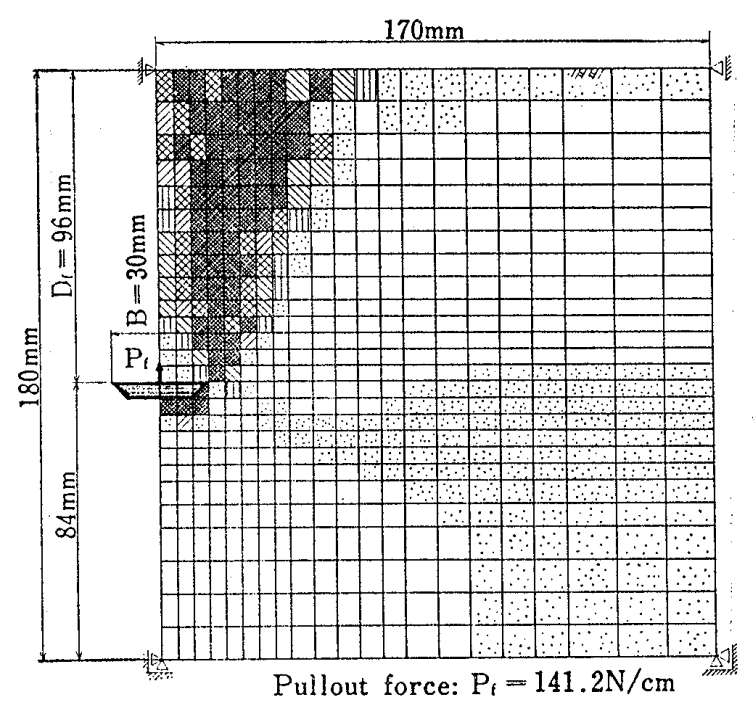

Fig. 9. Result of two-dimensional finite element analysis of shallow anchor (Spread of plastic zone)

considered to support the Meyerhof's assumption (1973) on a shallow anchor and that of this study on a deep horizontal anchor.

(2) The dimensionless ultimate pullout resistance $Q_{u} / A_{\gamma} G_{L} D_{f}$ by the finite element analysis is comparatively in good agreement not only with the theory of plasticity but also with the experimental values.

\section{8) Comparison with Various Theories and} Cther Data

Fig. 13 shows the comparison between the present theories, the results of the finite element analyses, and experimental data reported by other researchers. These experimental data by other researchers include those which

\begin{tabular}{|c|c|}
\hline Method of analysis & Two-dimensional F.E.M. \\
\hline Acceleration level & $\mathrm{G}_{\mathrm{L}}=92,3$ \\
\hline Name of soil & Ottawa Sand \\
\hline Condition of soil & $\begin{array}{c}\text { Dry dense } \operatorname{Dr}=76.7 \% \\
\phi_{1}=35.1^{\circ}, \gamma=16.8 \mathrm{kN} / \mathrm{m}^{3}\end{array}$ \\
\hline Width of anchor & $B=30 \mathrm{~mm}$ Relative depth \\
\hline Depth of anchor & $D_{1}=96 \mathrm{~mm} / D_{1} / B=3.20$ \\
\hline Inclination of anchor & $\alpha=0^{\circ}$ (vertical pullout) \\
\hline $\begin{array}{l}\text { Displacement of anchor } \\
\text { in pullout direction }\end{array}$ & $\delta=0.548 \mathrm{~mm}$ \\
\hline
\end{tabular}

Number of elements : 546

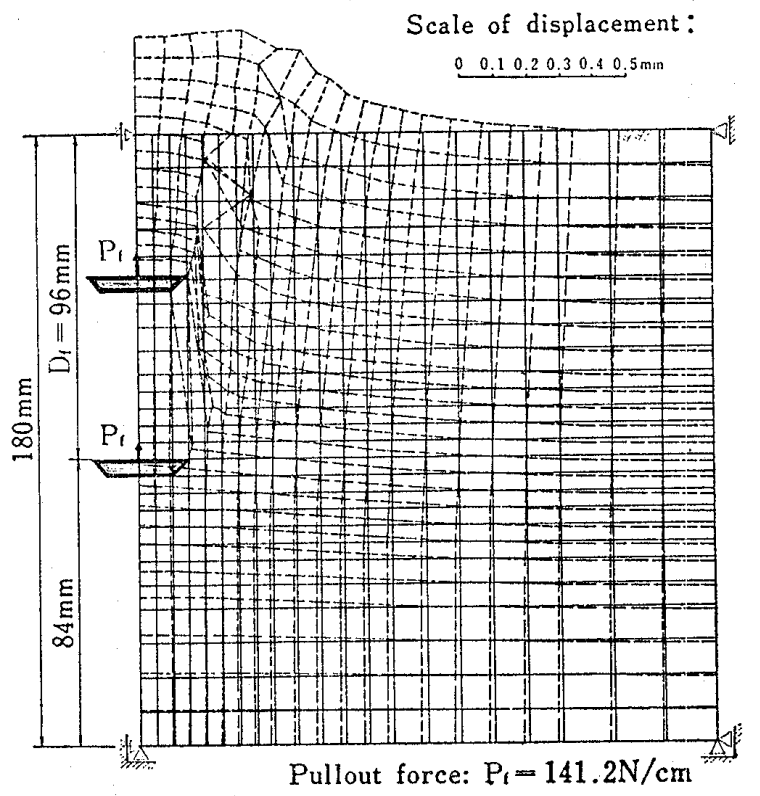

Fig. 10. Result of two-dimensional finite element analysis of shallow anchor (Displacement of anchor and deformation of soil)

have been obtained by a conventional model test in $1 \mathrm{~g}$ field, by a field test using a relatively small model $\left(D_{A} \leqq 1.1 \mathrm{~m}\right)$ and by a centrifugal technique at a low acceleration level $\left(G_{L} \leqq 40\right)$. These data, most of which are concerned with a three-dimensional anchor, have been plotted for comparison purposes after converting them by the shape factor into those concerned with a twodimensional anchor (strip anchor). Fig. 13 shows that most of the data by other researchers are greater than the values by the present theory, present data and the results of the finite element analyses, whereas some are in agreement with those by the present 


\begin{tabular}{|c|c|}
\hline Method of analysis & Two-dimensional F.E.M. \\
\hline Acceleration level & $\mathrm{G}_{\mathrm{L}}=94.9$ \\
\hline Name of soil & Ottawa Sand \\
\hline Condition of soil & $\begin{array}{l}\text { Dry dense } \operatorname{Dr}=76.7 \% \\
\phi_{\mathrm{d}}=35.1^{\circ}, \gamma=16.8 \mathrm{kN} / \mathrm{m}^{3}\end{array}$ \\
\hline Width of anchor & $\mathrm{B}=18 \mathrm{~mm}$ Relative depth \\
\hline Depth of anchor & $\mathrm{D}_{\mathrm{f}}=241.3 \mathrm{~mm}$ \\
\hline Inclination of anchor & $\alpha=0^{\circ}$ (vertical pullout) \\
\hline
\end{tabular}

Number of elements : 828

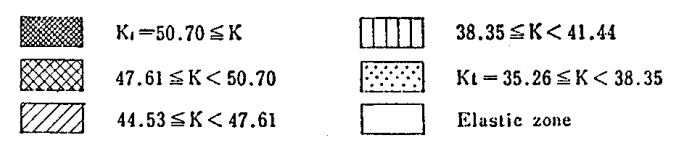

DII $41.44 \leqq K<44.53$

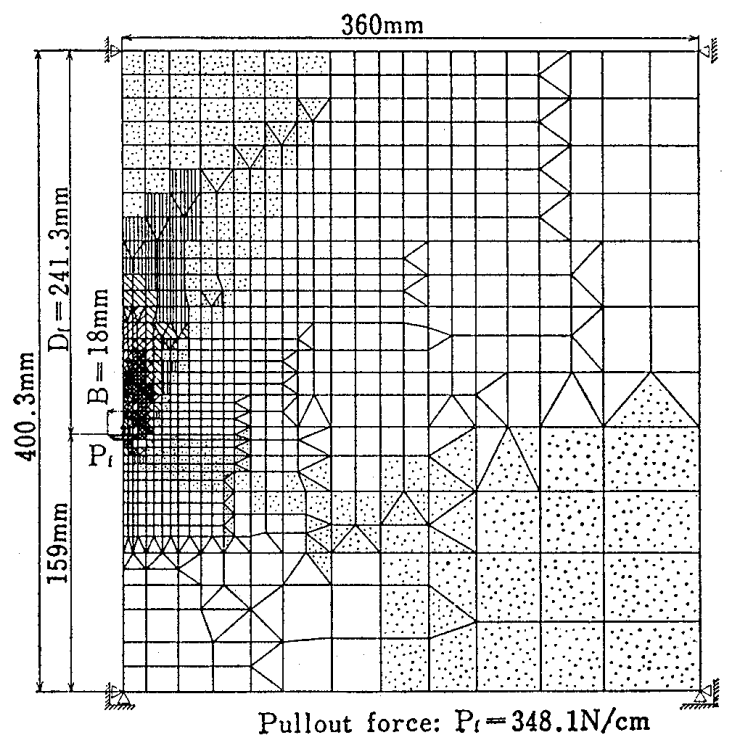

Fig. 11. Result of two-dimensional finite element analysis of deep anchor (Spread of plastic zone)

theory, probably because of the evaluation of angle of shear resistance $\phi$, the effect of the compaction of back-fill, etc.

Fig. 14 shows the comparison of pullout resistance of two-dimensional anchor with respect to the practical angle of shear resistance $\left(\phi=30^{\circ}, 35^{\circ}\right.$ and $\left.40^{\circ}\right)$, among the present theory, the theoretical values by Matsuo (1967, 1968) and Vesić (1971), and the experimental formula by the centrifugal technique by Ovesen (1981). In this figure, the theories of Matsuo $(1967,1968)$ and Vesić (1971) provide limits for the relative depth $D_{f} / B$ in the effective ranges of their

\begin{tabular}{|c|c|}
\hline Method of analysis & Two-dimensional F.E.M. \\
\hline Acceleration level & $\mathrm{G}_{\mathrm{L}}=94.9$ \\
\hline Name of soil & Ottawa Sand \\
\hline Condition of soil & $\begin{array}{l}\text { Dry dense } \mathrm{Dr}=76.7 \% \\
\phi_{\mathrm{d}}=35.1 ; \gamma=16.8 \mathrm{kN} / \mathrm{m}\end{array}$ \\
\hline Width of anchor & $B=18 \mathrm{~mm}$ Relative depth \\
\hline Depth of anchor & $D_{1}=241.3 \quad D_{1} / B=13.41$ \\
\hline Inclination of anchor & $\alpha=0^{\circ}$ (vertical pullout \\
\hline $\begin{array}{l}\text { Displacement of anchor } \\
\text { in pullout direction }\end{array}$ & $\delta=0.697 \mathrm{~mm}$ \\
\hline
\end{tabular}

Number of elements : 828 $\begin{array}{ccc}\text { Scale of displacement: } \\ 0 & 0.5 \quad 1.0 \mathrm{~mm}\end{array}$

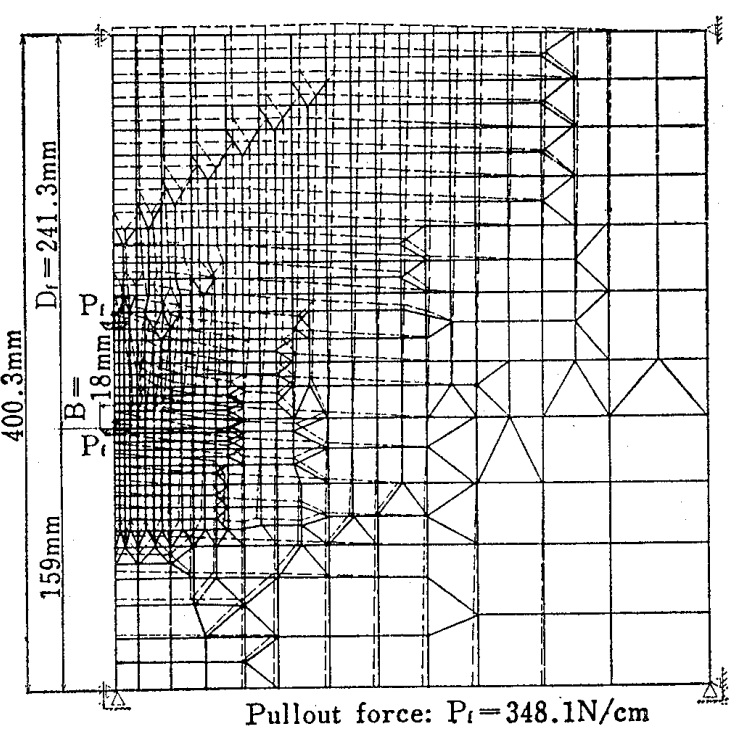

Fig. 12. Result of two-dimensional finite element analysis of deep anchor (Displacement of anchor and deformation of soil)

applications. The formulas of Matsuo (1967, 1968) and Ovesen(1981) for a circular anchor are compared by introducing the shape factor and by converting them into the twodimensional solutions. This figure describes the following:

(1) The estimated dimensionless ultimate pullout resistance $Q_{u} / A \gamma D_{f}$ becomes greater in the order of Vesić's (1971), Meyerhof's (1973) and present theories, Matsuo's (1967, 1968) and Ovesen's (1981), but there is little difference between Vesić's (1971) and theories by Meyerhof (1973) and authors of this 


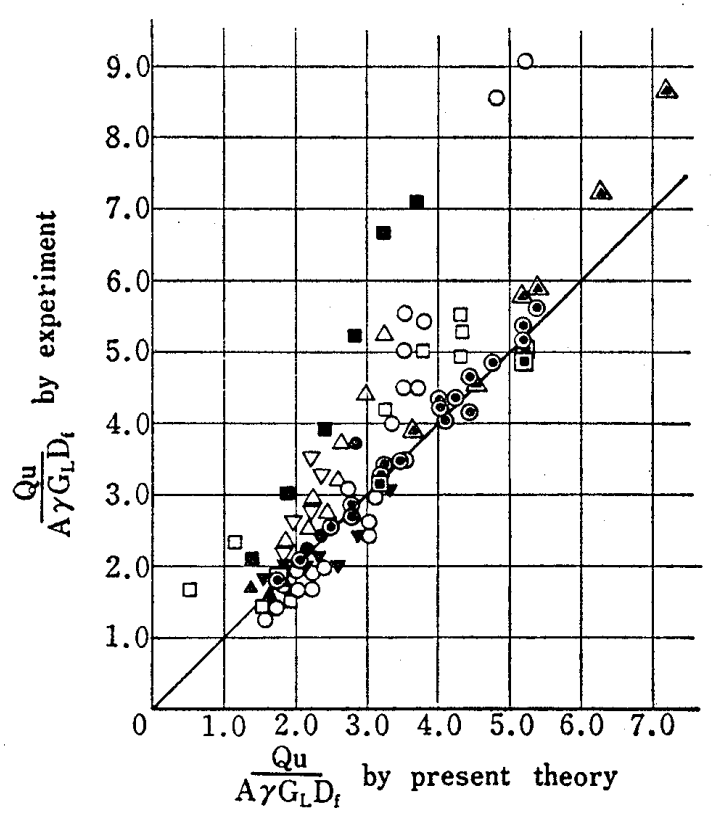

a) Inclination of anchor $\alpha=0^{\circ}$ (vertical pullout of shallow and deep horizontal anchers)

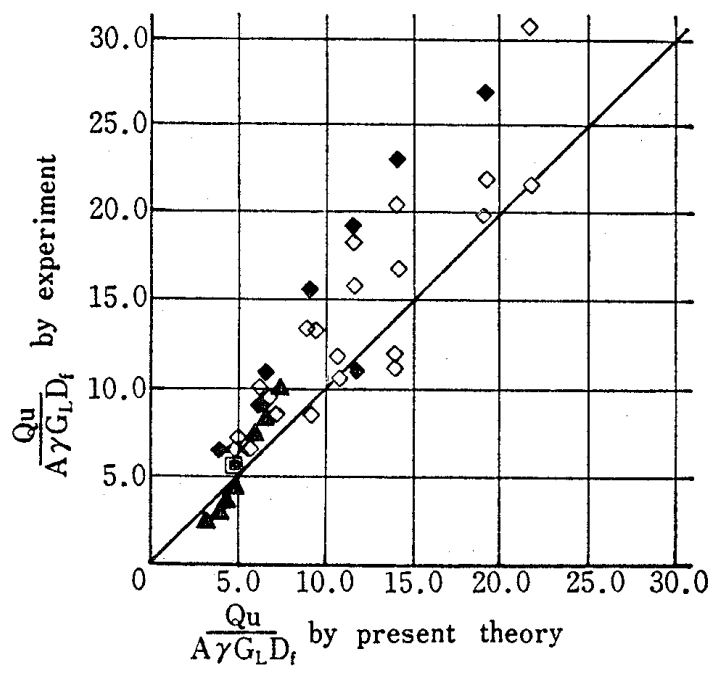

c) Inclination of anchor $\alpha=90^{\circ}$ (horizontal pullout of shallow vertical anchor)

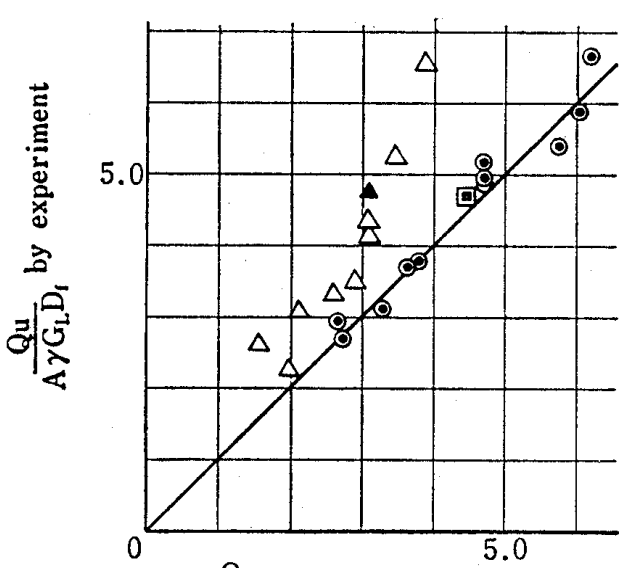

$\frac{\mathrm{Qu}}{\mathrm{A} \gamma \mathrm{G}_{\mathrm{L}} \mathrm{D}_{\mathrm{q}}}$ by present theory

b) Inclination of anchor $\alpha=45^{\circ}$ (shallow $45^{\circ}$-inclined anchor)

Researcher Acceleration level of test field $G_{L}$

Present $87.1-128.0$

$\Delta$ Present

40

$\square$ Present (F.E.M.) 92.3-100

Kananyan (1966) 1

Katsumi and

Nishihara (1978) 1

Balla (1961)

1

$\square$ Das and Seeley (1975)

- Ovesen (1981) 1

$\Delta$ Ovesen (1981) 37.5

$\checkmark$ Matsuo (laboratory test, 1 1969)

$\nabla$ Matsuo (field test, 1969) 1

- Dickin and Leung 20 (1983)

$\diamond$ Dickin and Leung $\quad 40$ (1983)

1
1
1
1
1
1
20
0

Fig. 13. Comparison among present theory, present test data, present F. E. M. analyses and various data by other researchers (The data converted into those of the two-dimensional anchor)

paper.

(2) The Vesić's solution (1971) is insensitive to a change in the angle of shear resistance $\phi$.

(3) The Ovesen's formula (1981) is greatly varied to a change in the angle of shear resistance $\phi$.

\section{CONCLUSIONS}

This paper introduced the theoretical formulas of the anchor pullout resistance 


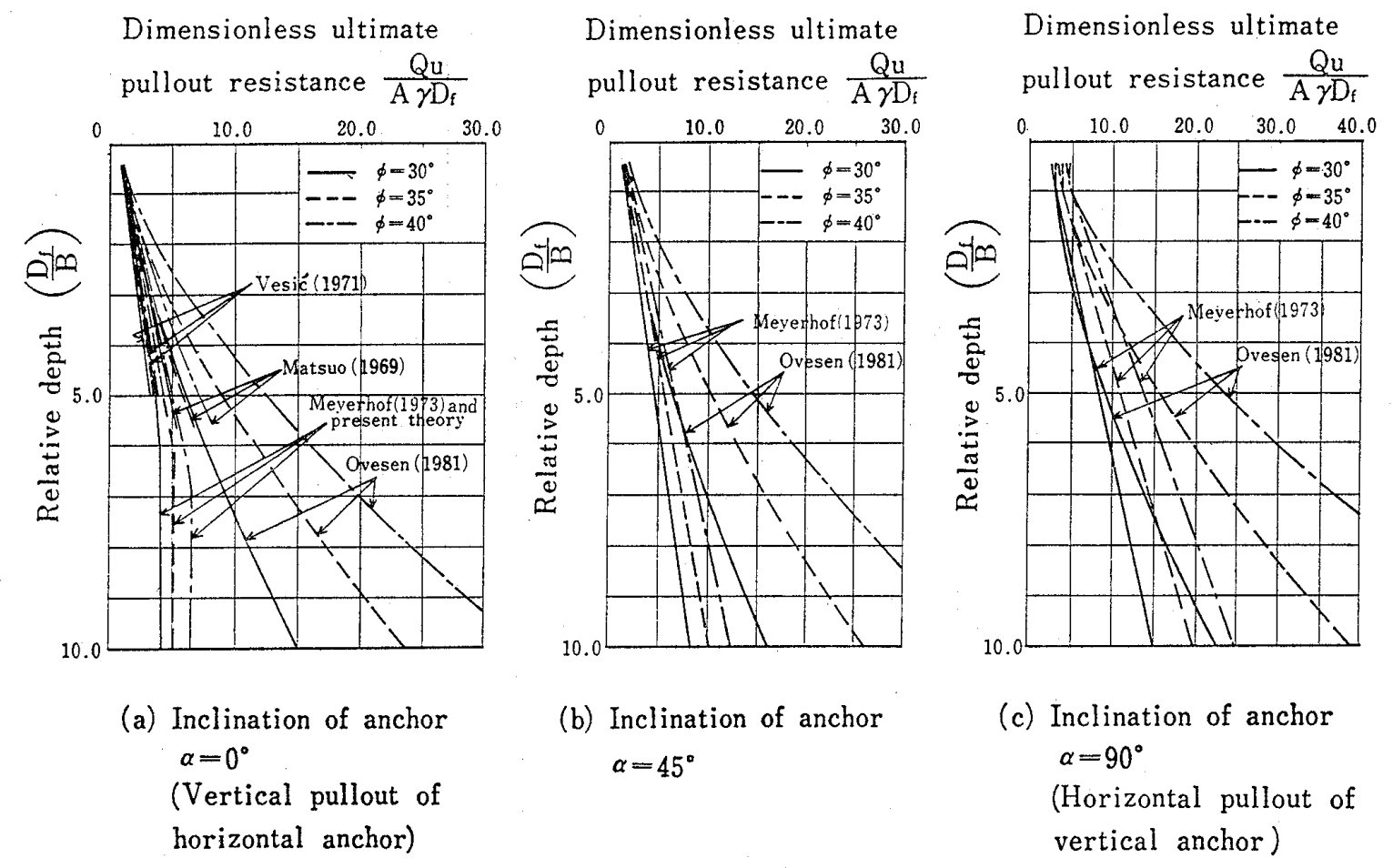

Fig. 14. Comparison of various theories and experimental formulas on anchor pullout resistance

in medium-to-dense sandy soil based on the theory of plasticity. Good agreement among the theories; experimental values, using the centrifugal technique, and the results of the finite element analyses was observed. The main conclusions are given, as follows :

(1) The solution by Meyerhof (1973) for the pullout resistance of shallow anchor and the theoretical formula of deep horizontal anchor by the theory of plasticity using the concept of cavity expansion show the good agreement with the results of centrifugal model tests and the elastoplastic finite element analyses based on the Lade's constitutive law (1972, 1975, 1976).

(2) The dimensionless ultimate pullout resistance $Q_{u} / A_{\gamma} D_{f}$ is almost linearly increased in the shallow region as the relative buried depth of anchor is increased and becomes constant from a certain relative depth.

(3) The shape effect of the rectangular anchor, having a finite length, can be explained by introducing the shape factor $S_{h}=1.0+B / L_{A}$.

\section{NOTATION}

$A=$ area of anchor

$A_{1}, A_{2}=$ constants for $K_{2}$ indicating dilatancy characteristics in Lade's constitutive equation

$B=$ width of anchor, or effective width of circular anchor

$D_{A}=$ diameter of circular anchor

$D_{f}=$ depth of anchor center

$D_{f c r}=$ critical depth of anchor

$\left(D_{f} / B\right)_{c r}=$ critical relative depth of anchor

$D_{0}=$ maximum depth of anchor

$E_{u r}=$ unloading-reloading modulus in Lade's constitutive equation

$\bar{F}_{q}=$ cavity expansion factor

$G_{L}=$ acceleration level in centrifugal field

$I_{r}=$ rigidity index of soil

$I_{r r}^{\prime}=$ reduced rigidity index

$K=$ stress level defined as $I_{1}^{3} / I_{3}$ in Lade's constitutive equation

$K_{b}=$ uplift coefficient of shallow anchor

$K_{f}=$ value of $K$ at failure in Lade's constitutive equation

$K_{t}=$ value of $K$ at threshold for plastic straining in Lade's constitutive equation

$K_{u r}=$ unloading-reloading modulus in Lade's constitutive equation 
$L_{A}=$ length of anchor

$l=$ exponent in Lade's constitutive equation

$M=$ constant in Lade's constitutive equation

$N_{q}=$ uplift coefficient of deep anchor

$n=$ exponent in Lade's constitutive equation

$P_{f}=$ pullout force

$Q_{u}=$ ultimate pullout resistance of anchor

$Q_{u d}=$ ultimate pullout resistance of deep anchor

$Q_{u s}=$ ultimate pullout resistance of shallow anchor

$q_{0}=$ ultimate pullout resistance per unit area of anchor

$\bar{q}=$ mean effective ground stress

$R_{f}=$ failure ratio in Lade's constitutive equation

$S_{c}=$ shape factor of circular anchor

$S_{h}=$ shape factor of anchor

$S_{s q}=$ shape factor of square anchor

$S_{s t}=$ shape factor of strip anchor

$W_{A}=$ effective weight of anchor

$W_{S}=$ effective weight of soil above anchor

$\alpha=$ inclined angle of anchor or load inclination from vertical (degrees)

$\gamma=$ effective unit weight of soil at $1 \mathrm{~g}$ field

$\Delta=$ volume change parameter

$\delta=$ displacement of anchor in pullout direction

$\bar{\sigma}=$ ultimate pressure needed to expand cavity

$\sigma_{V}=$ initial vertical ground stress

\section{REFERENCES}

1) Balla, A. (1961): "The resistance to breakingout of mushroom foundations for pylons," Proceedings of the Fifth International Conference on Soil Mechanics and Foundation Engineering, Paris, France, Vol. I, pp. 569-576.

2) Jaky, J. (1944) : "The coefficient of earth pressure at rest," Journal of the Society of Hungarian Architects and Engineers, pp. 355-358.

3) Katsumi, T. and Nishihara, A. (1978): "Fundamental studies on pullout resistance of earth anchors," Proceedings of the Japan Society of Civil Engineers, Vol.276, pp.65-76 (in Japanese).

4) Katsumi, T. and Nishihara, A. (1980): "Fundamental studies on pullout resistance of inclined earth anchors," Proceedings of the Japan Society of Civil Engineers, Vol.295, pp. 41-50 (in Japanese).

5) Lade, P. V. (1972): "The stress-strain and strength characteristics of cohesionless soils,"
Thesis presented to the University of California at Berkeley, California, for the Degree of Doctor of Philosophy.

6) Lade, P. V. and Duncan, J. M. (1975): "Elastoplastic stress-strain theory for cohesionless soil," Journal of the Geotechnical Engineering Division, American Society of Civil Engineers, Vol. 101, No. GT 10, October, pp. 1037-1053.

7) Lade, P. V. and Duncan, J. M. (1976) : "Stresspath dependent behavior of cohesionless soil," Journal of the Geotechnical Engineering Division, American Society of Civil Engineers, Vol. 102, No. GTl, January, pp. 51-68.

8) Matsuo, M. (1967): "Study on the pullout resistance of footing (I)," Soils and Foundations, Vol. 7, No. 4, pp.1-37.

9) Matsuo, M. (1968): "Study on the pullout resistance of footing (II), " Soils and Foundations, Vol. 8, No.1, pp. 18-48.

10) Meyerhof, G. G. and Adams, J. I. (1968): "The ultimate uplift capacity of foundations," Canadian Geotechnical Journal, Vol. V, No.4, pp. 225-244.

11) Meyerhof, G.G. (1973) : "Uplift resistance of inclined anchors and piles," Proceedings of the Eighth International Conference on Soil Mechanics and Foundation Engineering, Moscow, Union of Soviet Socialist Republics, pp. 167172.

12) Ovesen, N. K. (1981): "Centrifuge tests of the uplift capacity of anchors," Proceedings of the Tenth International Conference on Soil Mechanics and Foundation Engineering, Stockholm, Sweden, Vol.1, pp.717-722.

13) Tagaya, K., Tanaka, A. and Aboshi, H. (1983): "Application of finite element method to pullout resistance of buried anchor," Soils and Foundations, Vol.23, No. 3, pp. 91-104.

14) Vesić, A.S. (1965) : "Cratering by explosives as an earth pressure problem," Proceedings of the Sixth International Conference on Soil Mechanics and Foundation Engineering, Montreal, Canada, pp. 427-431.

15) Vesić, A.S. (1971): "Breakout resistance of objects embedded in ocean bottom," Journal of Soil Mechanics and Foundation Division, Proceedings of American Society of Civil Engineers, Vol.97, No. SM 9, pp. 1183-1205.

16) Vesić, A.S. (1972): "Expansion of cavities in infinite soil mass," Journal of Soil Mechanics and Foundation Division, Proceedings of American Society of Civil Engineers, Vol. 98, No. SM 3, pp. 265-290.

17) Vesić, A.S. (1975) : Principles of Pile Founda. 
tion Design, Soil Mechanics Series No.38, School of Engineering, Duke University.

18) Yamaguchi, H. (1972): "Some discussion on coefficient of earth pressure at rest," Proceedings of the Twenty-seventh Annual Conference of the Japan Society of Civil Engineers, III36 , pp. 109-110 (in Japanese).
19) Yamaguchi, H., Kimura, T. and Fujii, N. (1977): "On the scale effect of footings in dense sand," Proceedings of the Ninth International Conference on Soil Mechanics and Foundation Engineering, Tokyo, Japan, Vol. I, pp. 795-798. 